Nándor Máté Dr. Birher - Eszter dr. Batka dr. Söréné - Edit Knoll-Csete

\author{
Doctoral School of the Faculty of Law of the Gáspár Károli University of the Reformed \\ Church in Hungary
}

\title{
CONTROL COMPLEXITY: RELATIONSHIP INSTEAD OF COMPETITIVENESS
}

\begin{abstract}
Justice, which is one of the key concepts of morality on which cultures of thousands of years are built, cannot be excluded from law by one sentence. Instead, this concept must be transformed partly into legality, and the relationship between law and morals, for example, must be systematically analyzed, for example, on the question of justice. In view of the position of rational knowledge, there are only interests and conflicts of interest, which are resolved by an order of interests which satisfies one interest against the other at the expense of it, or creates an agreement or compromise between conflicting interests. However, the fact that only one or the other such order would be of absolute value, "just", cannot be justified by rational knowledge. There is no "pure law", or liberal or conservative values will be decisive for legal decisions as well. Therefore, there can be no objective of pure law, but the aim may be to ensure that the norms of morality and religion are properly channeled into legal practice. Artificial Intelligence will change society. It will open opportunities, but also risks as well. The norm of morality means, on the one hand, that Artificial Intelligence must be controlled and approved by a human being, and on the other hand, it must be said that it is not possible to do everything technically possible because of the peculiarities of human existence. "A year spent in artificial intelligence is enough to make one believe in God." It is not easy to find a way out in the density of norms. Trust is now weakened in all norms, but at the same time, our self-awareness has increased. Knowing and accepting other rights, morals and religions does not mean that our own norms are weakened. In fact, on the contrary: acceptance of differentness strengthens us.
\end{abstract}

\section{Installation}

It is well known that, in the course of the functioning of the Constitutional Courts, openly political aspects and, in this connection, ethical aspects are increasingly coming to the fore. The question is explored in detail, in the study of Béla Pokol, "Doubling of the legal system". "Can politically neutral constitutional thematic be consolidated?" "Asks the author, after an in-depth analysis, which basically means can there be a "clear constitutional doctrine and practice?" The answer is clear and sobering - compared to the ideals that were expressed even a few decades ago. "... if it may not in principle be impossible to establish a more consolidated and politically neutral constitutional thematic with conceptual distinctions and argument formulas divided, according to logical coherence, but this requires a number of lucky coincidences... in principle, such neutral constitutional thematic should not be presumed in investigations today. ${ }^{1 “}$ 
As Kelsen and his contemporaries dreamed about, at the "upper end" of the law, it is becoming less and less possible to hide the idea that there is no neutrality, clearly fixed and fixable rules of the game 2 ."Pure Legalology is a jurisprudence, not a legal policy," says Kelsen ${ }^{3}$.

With the help of law, seemingly clear processes can solve the regulation of human behavior. Facts can be adjusted to the law in a regulated manner.

"That a certain congregation of men: Parliament and the result of their operation: Law, or in other words, that such events make such a 'point' only means that the whole facts comply with certain provisions of the Constitution. So that the content of an actual event is the same as a standard which is supposed in some way. 4 “،

According to pure legalology, law is the product of an intellectual process and, as such, is well characterized in itself, no external interpretation horizons are necessary. On the "input side" of the law, we find the Constitution and in the "output", we find judicial practice, regardless of any additional horizon of interpretation.

"But no one can deny that the law as a norm is spiritual, not a natural reality. At the same time, we are presented with the task of distinguishing the law from other norms - as well as from nature, from other spiritual phenomena - but especially from other norms. Here, first and foremost, we must free the right from the relationship with which it has been bound from the beginning to morality. Of course, this is not at all a rejection of the claim that the law is. This claim goes without saying; what it really means is another matter. It is only to be rejected that law as such is a component of morality, that every right as a right must be to a certain extent and in a sense moral. ${ }^{5 ،}$

The purge of the law from other norms is an essential step in modernity thinking in structures and "machinery". At first, the principle seems indisputable: what can be regulated must be clearly regulated.

Later, however it turns out that the clarity of the regulation - partly due to epistemological reasons and partly for theory of existence - cannot be blamed purely for causal processes, for example because one interprets duty as Kant. There is always a difference between general concepts and individual facts and between events and the facts described there from them. In this sense, the clear process of law can only be partially capable of regulating the life of the community. Therefore, the law must not exclude non-legislative norms from regulated communities or even ignore them.

For all norms, it is essential to be able to establish patterns of relationships with other norms while preserving the autonomy of its operation. No legal order can banish the truth from its system of interpretation, calling it an "irrational idea."

In view of the position of rational cognition, there are only interests and conflicts of interest, the resolution of which occurs through an order of interests that settles one interest over another at the expense of it, or creates an agreement and a compromise between opposing interests. However, the fact that only one or the other such order would be of absolute value, i.e. "just",

2 For more than two decades, I have undertaken to develop a pure law theory, purged of all political ideologies and elements of natural science, aware of its peculiarity, i.e. the self-legality of its subject. From the outset, my goal was to raise the jurisprudence, which, openly or implicitly, had been dissolved almost entirely in law-political reasonings, to the height of real science and real spirit science. Kelsen, H., Pure Law, Budapest 1988, XIX.

3I.M. 1.

4I.M. 3.

$5 \operatorname{Im} 7$. 
cannot be justified by rational knowledge. If there were justice in the sense in which its existence is invoked, whenever certain interests are to be asserted against other interests, then the positive right would be completely redundant, and its existence would be utterly intangible. In contrast to the existence of an absolute good, i.e. already the existence of a social order derived from nature, reason, or divine will, the state legislature's activity would be the worst attempt of artificial lighting in bright light day. So, the usual excuse - that there is justice, can only be defined (or what is the same: it cannot be determined unanimously) - it is selfcontroversy, and this is a typical ideological obscuration of the real, very painful reality. Justice is an irrational ideal. However indispensable it may be for human will and action, it is not accessible to cognition ${ }^{6}$.

Each norm order must interpret the basic concepts of other norms and develop the methodology for this interpretation within their own coding system. Justice, which is one of the key concepts of morality on which cultures of thousands of years are built, cannot be excluded from law by one sentence. Instead, this concept must also be partially legal and, in part, the relationship between law and morality must be systematically analyzed. For example, on the issue of the perception of justice. In the same way, the norm of morality must interpret fundamentally the legal categories of human rights or even the rule of law. It is precisely the norm of morality that should be prevented - for example - from politicizing the concept of the rule of law, within the norm of law to such a level that it is light years from its original meaning. We stress that if this happens, it is not so much a dysfunction of morality as a dysfunction of law as a norm order at least in the first step.

The appointment of Amy Coney Barrett, judge of the U.S. Supreme Court, was a special place to raise awareness of the law process. Before we present this, we note that raising awareness of the process of law means making the process of law fully aware (racialization) and opportunistic intervention in the process. All this is, if possible, we will also rewrite the rules of the game. For example, election geography, politicized candidacy in each branch of power, or even election fraud and countless similar methods. This then leads to a weakening of trust in the norms of law.

This is precisely why it may be necessary - which is persecuted by pure legality - for the norm of law to be linked to other, in many respects, more abstract norms, such as morality, or, as we see in other cultures, religion.

Going back to our previous example, it is clear that within a purely legal norm, ethical and even religious elements appear chaotically in the form of political pressure. Barett is a respected lawyer, but part of his appointer, and partly because of his moral and religious beliefs, it is clear what his legal position will be on certain issues, such as gender or abortion.

There is no "pure law", or the liberal or conservative values will also be decisive for legal decisions. A pure law cannot therefore be an objective, but it may be an objective to properly channel morality or the norm of religion into legal practice. Instead, we can hear, typically from the liberal side, the need to completely ban morality from the law. By looking at Barrett's example, you may know what the decision for example the abortion issue will be. On the other hand, moral judges are banned along with morality; there will be another liberal morality, in which it is also known in advance, what the decision will be made... The difference in our case is that liberal morality is not called morality, or atheism by the force of religious beliefs is not called materialistic religion. Instead of half-page explanations, we need to face the truth and 
establish an appropriate system of relations between norms. The first step is to speak clearly about norms. To illustrate the conceptual chaos, here are a few sentences from the daily press:

Liberals are concerned that Barrett is a member of a charismatic Christian community that opposes same-sex relationships, follows the teachings of the New Testament, promotes a strict patriarchal hierarchy, and potential sees many progressive movements as the devil's work. They raise the question: how will your past, or who will influence it, if you have to decide, for example, on same-sex marriage or the right to abortion? In general, it is also a question of how the Constitution can be interpreted in the spirit of the founding fathers more than two hundred years ago. ${ }^{7 / 6}$

The law, while gradually breaking through stereotypes of attachment to the state, is obviously linked to more and more other levels of regulation, which sometimes take on the mask of 'politics'. In fact, however, it is becoming increasingly clear that the human community is regulated in cooperation with different norms, and it is an illusion to think that only the rule of law can be classified under the rule of law.

\section{Each level of regulation}

In the following, we will outline the levels of regulation that can be distinguished. Each level of regulation has a separate code and human co-living can be treasured as a different reality. In different realities, individuals experience the process of regulation in different ways (experience). The content of the regulatory levels can also be recorded in very different ways, from the collective narrative philosophy to those described in binary codes.

\begin{tabular}{|l|l|l|l|}
\hline Level of regulation & Code & Reality & Experience \\
\hline religion & Holy/profane & transcendental/immanent & blessing/crime \\
\hline ethics & good/bad & $\begin{array}{l}\text { conscience/ } \\
\text { "disposition” }\end{array}$ & pride/shamed \\
\hline society Ethics & Fair/unjust & good State/Fever State & Community/Self \\
\hline right & Right/Unlawful & factual/subjective & reward/harassment \\
\hline $\begin{array}{l}\text { algorithm } \\
\text { procedure) }\end{array}$ & true/false & consistent/defective & $\begin{array}{l}\text { working/not } \\
\text { working }\end{array}$ \\
\hline
\end{tabular}

The debate as to whether there are moral elements in the law or whether the rules of morality are legal (like common law) is actually meaningless Rather, the question is how, through individuals and the community of individuals, individual norms can be connected to the whole that shapes the future, without impairing their methodological purity.

In recent scientific research, a multitude of definitions have appointed with sufficient precision what is law, morality, or religion. In this area, the brilliant work of Hermann Schmitz, titled "Der unerschöpfliche Gegenstand" (The inexhaustible object), which describes norms with the philosopher's methodology, is particularly enjoyable. It is particularly forward-looking that he referred to the fact that he detailed the law in the second part of the chapter on morality in his 
referenced work, and then, in the subsequent chapter, religion, specifically the "divineTheology" ${ }^{18}$.

However, there is a lack of definitions that describe the relationship between these norms with sufficient clarity. Instead, we hear either that the norms are completely independent of each other, so much so that, no judge can have either religion or morality as a judge. Moreover, these norms "overlap", so there is no sharp boundary between the boundaries of religion, morality, and law. András Tamás feels it correctly - although he does not yet describe the exact contexts - that the "modern political state is se worldly morality and politics. He also points out that the political state is the custodian of order and freedom, but it seems precisely to this day that this function is becoming increasingly difficult to fulfil purely with the help of the legal norm ${ }^{9}$.

The current dysfunctions of democracies, the most significant of which are demographic catastrophe, inequalities, and environmental disasters, which partly result from them, are a source of public confidence in the law. This process is also made up of the fact that globalization processes go far beyond the national framework of modern political states, since the data and information assets on which societies operate are practically common, despite all efforts to the contrary.

The detected dysfunctions in the field of regulation have initiated two counter-re-regulation processes. However, the two opposite directions will probably meet once the thinking "circles" after all. One direction is increasingly formal regulation. This, as we have repeatedly demonstrated, offers the illusion of objectivity, but at the same time, it is unsuitable for the unfairness. ${ }^{10}$. The other direction, moving away from the objectivity of the law, is to look for ways to regulate coexistence more effectively that seeks to establish a framework for regulation along the lines of moral or even religious content. Codes of ethics and codes of conduct that describe possible ways of cooperation are increasingly important in international relations. Here, the rules are often not item phrases, but rather a kind of self-assessment reflection. A similar phenomenon can be seen in religiously based patterns of community behavior leaking into Western culture. On the one hand, therefore, strictly formalized standards and, on the other hand, regulators that prefer community life are tightening up state legal order.

Lawyers of the next era will have to face the fact that their profession is becoming increasingly out of the way. Typing no longer means not only industrially produced legislation and machine search engines, but also automated decisions based on artificial intelligence that fully implement appearance objectivity in individual decision-making situations, whether in the course of public administration or the functioning of the courts. For the time being, it is still in the category of legend, but the AI, called Prometea, is becoming more effective, which can decide on rights issues that are more accurate than human beings. ${ }^{11}$.

(Another question is that in many cases the essence of a judicial decision is to make a decision, not to be a "just" decision.) It is also a fact that if the judicial verdicts or even the entire trial material become more accessible, it will become easier to understand the habits of the judge, to create his profile, and thereby to make submissions that can influence the decision. Judge analysis may seem like an obvious method in cases of significant litigation value, and with the help of technology, any interested party has every opportunity to do so. There are some places

\footnotetext{
8Schmitz, H., Der unerschöpfliche Gegenstand, Bonn, 1995, 321-438.

9 www.pewforum.org/2019/07/15/a-closer-look-at-how-religious-restrictions-have-risen-around-the-world/, downloaded 2020.11.24.

10Birher N., when can the ecclesiastical judge rule against Canon law? Budapest 2000.

11Corvalán, G., Artificial Intelligence, Threats, Challenges and Opportunities Prometea, the First Predictive Artificial Intelligence at the

Service of Justice is Argentinian, in IMODEV 2018 vol. 4, www.ojs.imodev.org/index.php/RIDDN/article/view/256/417, 2020.10.30.
} 
where they are trying to criminalize this activity, but how can a law or decision-finding and analysis algorithm be found?

At the same time, the perhaps more important question is raised: who, by what right and responsibility, programmes AI or physical machines Who, by what right and with what responsibility, creates rules for them? Can any parliament see through these ways of regulation?

At this point, we have already reached the norm of morality, which means, on the one hand, that AI's activities must be controlled and approved by a human being (moral, i.e. an existing being with will and consequently responsibility), and on the other hand, it must be said that it is not possible (free) to do everything technically be done because of the peculiarities of human existence. This has led to a clear (redefined) definition of man and the development of decisionmaking forums that are defined not only by law, but also by morality ${ }^{12}$ and, neatly by religion.

Advances in technology have overridden the modern framework of legislation, seemingly in place for hundreds of years, and led man back (if he wants to survive) to the norms of morality and religion.

This is precisely why who can be a member of the higher courts is gaining (and politicized) importance. As we have already pointed out, the norms of religion are not negligible either, as more and more communities identify themselves along the lines of a religious affiliation. In the light of demographic changes, it is clear that religious breeding and non-religious are extinct. ${ }^{13}$.

Because of this fact, religion has also (unfortunately) become a state identity issue in recent times, leading to a global increase in anti-religiousism. Christianity was particularly well understood in this area. ${ }^{14}$. It is peculiar that other religions are not necessarily the biggest challenge to Christianity, but rather social media and internet hate speech. ${ }^{15}$ It is also of the remit of these trends that it is of paramount importance that the relationship between religion and law is explored as clearly as possible from the point of view of the State.

As a practical example, it may be expected that the judge may have a certain moral basis, but at the same time it is also expected that his decisions will be taken in accordance with the rules of law. In most cases, this is not a problem since both law and morality have the same common sense and free will foundations for the survival of the community. However, there may be inconsistencies. In these cases, however, the codes and internal regularity of law or morality should not be confused. It must be stated that the norms of law and morality conflict with each other. If this conflict cannot be resolved, the judge is prohibited from making a moral decision, just as it is forbidden to make a decision on a legal basis. In these cases, you cannot take the decision and you must return the case.

12Communication from the Commission to the European Parliament, the European Council, the Council, the European Economic and Social Committee, and the Committee of the Regions

Artificial intelligence for Europe, 2018, www.ec.europa.eu/digital-single-market/en/news/communication-artificial-intelligence-europe, 2020.10 .30 .

13the changing global religious landscape, babies born to Muslims will begin to outnumber Christian births by 2035; people with no religion face a birth dearth, www.pewforum.org/2017/04/05/the-changing-global-religious-landscape/, 2020.10.30.

14 www.pewforum.org/2019/07/15/a-closer-look-at-how-religious-restrictions-have-risen-around-the-world/, 2020.10 .30$.

15 www.bmz.de/religionsfreiheit/de/der-bericht/zweiter-religionsfreiheitsbericht.pdf, 2020.10.30. 
Moreover, higher courts may be partially entitled to resolve a similar conflict of law by simultaneously treating the concept of political morality and law at the same time. In these cases, too, it is wrong to think that judges would act purely based on the rules of law. It is simply that the higher courts act in accordance with the norms of law and morality at the same time, both lawyers and the 'council of wise men'. However, this must be made clear in the face of today's vague practice and the related powers to be secured. This clear vision could also be the basis for these for a to be able to cooperate in substantive decisions not only at national level but also at international level. The international network of higher courts could be used to establish a global meaningful cooperation, since the communication of professionals with experience in both law and morality, who can interpret the two norms, has a good chance of producing usable output results.

\section{Regulatory complexity and civilization}

It is customary to treat Western civilization, separated from Christianity, as some kind of legaleconomic unit that has tried to subdue other civilizations, but whose failures are becoming clearer. ${ }^{16}$. The successes and then the continued failures of the early 1900 s led to the need for global mutual communication to take the place of self-debating western civilization, which will also take place in a changed regulatory framework.

"The great religions of the world are all products of non-Western civilizations and, for the most part, predates Western civilization in time. As the world moves out of its western part, the distinctive ideologies of Western civilization are in disreplained and replaced by other culturally based forms of religion, identity, and commitment. The separation of religion and politics in Westphalia, i.e. the idiosyratic product of Western civilization, is coming to an end, and religion ... international events. ${ }^{176}$

Without going deeper into the question of civilization or culture, we can conclude that norms and their relationship play a decisive role in the formation of civilizations. If Western civilization can still have a future, it will surely be embodied in how western people find a sustainable relationship between norms. As we saw in the time of peace in Westphalia, religion alone cannot be a force organizing civilization, and morality has been revealed in the case of civil or worker-moral ideologies such as enlightenment and communism. Today, it is demonstrated that the rule of law does not create a reliable community on a historical scale. Huntington explains at length that the civilizations of the future will be built on urbanized, religious people who respect the advances of technology. According to him, these civilizations take the lead, and perhaps even the place, of Western civilization. ${ }^{18}$.

It is a compelling narrative, but as a member of Western civilization, we may not have to acknowledge this vision of demo's cation without a word.

In terms of the definition of civilizations, Huntington has already referred to it in terms of the survival of Western civilization, as we have pointed out in our analysis of regulatory complexity. The definition of civilizations clearly includes all the norms: In a world in which cultural identities - ethnic, national, religious and civilization - play a central role... ${ }^{19 ،}$ Instead

16Huntington, S., The clash of civilizations and the transformation of world order, Budapest 2014, 55, 69.

17I.M.:72 TO 73.

$18 \mathrm{UO}$.

19I.M.:532, and 532-550, chapters "The West and the World". 
of fighting individual norms (otherwise defining civilization), the full spectrum of norms should be aligned and co-operated. More clearly, proper communication with other civilizations is impossible without clarifying its own religious, moral, and legal identity. It is not enough to rely solely on one or other norms, or to think that they could be ignored in the functioning of individual civilizations. It is naive to think that religious and unreligious conduct is "similar" or that legal norms simply override religious norms. I like the Christian and the Muslim, I don't like him thinking differently, his religion rules differently. It is not the task of imposing legal ones in place of religious rules, since this has never been successful in history, martyrs bear witness. The task is to be able to harmonize the rules of the norms in some higher order, and in each of the norms, along the order of values translated into its own language. All this is possible if we remain within the limits of common sense. All religious people can be explained that killing the innocent is a sin. It is more difficult, of course, that the fetus is not human or that the man is not a man and the woman is not a woman. It may be worth a try, but I am sure that the harmony of norms can only be achieved if we know and live from the inside what is religion, morality and law."...the beliefs of the universality of the West in the age of civil wars face three problems: These views are false, immoral and dangerous. ${ }^{20 ، 6}$

Given our population indicators and the evolution of our politics, we must recognize to all Westerners that the "false, immoral and dangerous" worldview is also unviable. There can be no other way than to recognize this fact in order to return to the basic value, namely the true core value of Western civilization, the Tora, and the Christianity that we have survived. The importance of all this is underlined by the fact that this is precisely the value on which Europe has unified 'constitution' has run aground in recent decades.

The world has undoubtedly become multicultural. There is also no doubt that Europe or the US are no longer at the heart of this. This can be achieved by the joint minimum being set and the basis for all norms in the form of both the principles and the multicultural organizations that formulate them.

International power lines are shifting. There is no doubt that China is trying to take the lead and states such as India, Brazil, Saudi Arabia, as well as state groups such as the African Union ${ }^{21}$ and the Association of Southeast Asian Nations (ASEAN) ${ }^{22}$ have gained a greater influence. Chinese spacecraft landed on the Moon and returned with rock patterns ${ }^{23}$. Asian countries are exemplary in the management of the pandemic that hits the world, as well as in technological development. However, can we continue to evolve without further damage to our environment and proper legal regulation on matters of morality as well? Jo Biden, the new President of the United States hours after he was sworn in, announced the US re-enter the Paris climate accord, the landmark international agreement signed in 2015 to limit global warming. ${ }^{24}$ Space junk left behind by humans not only in the Earth as a huge plastic island in the middle of the North Pacific Gyre, the Great Pacific Garbage Patch, but it has formed the equivalent of this in low-

20I.M.:536.

21 www.au.int 20.01.2021

22 China and 14 other countries agreed on November 15th 2020 to set up the world's largest trading bloc, encompassing nearly a third of all economic activity, in a deal many in Asia are hoping will help hasten a recovery from the shocks of the pandemic.

23 China's Chang'e-5 mission is the third ever to bring back soil or rock samples from the Moon - only the U.S. and the former Soviet Union have accomplished that so far. The mission landed on the side of the Moon closest to the Earth.23.11.2020

24 www.nbcnews.com/science/environment/biden-rejoins-paris-climate-pact-scientists-hope-best-yet-come-n1255070 22.01.2021 
Earth orbit. ${ }^{25}$ The Protocol on Environmental Protection to the Antarctic Treaty (ATS) ${ }^{26}$ will end 2048; we have to find solution because Antarctica shall be used for peaceful purposes only. Will we be able to survive ourselves? Will world religions be able to reform their views, will they be able to follow the stunning change of the world and give adequate answers to the challenges posed by modern man? The United Nations has declared 2021 as the International Year of Peace and Trust, the International Year of Creative Economy for Sustainable Development. 2021 will also be the year when acceptable and convincing answers must be given to the questions raised by the actions taken in the management of the COVID-19 pandemic in order to combat the pandemic and return to normal life through a joint collaboration.

Principles and organizations must be based on common human nature and common sense. "The only way for a multi-civilization world to develop is to renounce universalism and recognize diversity and seek common characteristics. ${ }^{27 ،}$ That this is not just a dream, Huntington is bringing the example of Singapore, where the following core values have been formulated to underpin the recovery:

- The nation is ahead of the ethnicities that make up the nation, society, or the individual

- family is the most basic unit of society

- the individual deserves respect and the community has a duty to support

- instead of violent solutions, consensus should be sought

- principle of harmony between ethnicities and religions

\section{Joint management of norms of law, morality, and religion along the lines of solidarity}

It raises the question of the principles under which the relationship of norms could be established in the present situation of the world. Today, the following facts are becoming clearer and more pronounced:

- the thinking of modernity has moved from the endless enthusiasms of technology to the experience of unsustainability, which is reflected both in environmental unsustainability and in the social injustice resulting from the blatantly unequal distribution of wealth,

- the indigently destructive pandemic has demonstrated the global destiny of societies and the fact that, contrary to beliefs, both the individual and the scientific community are ultimately powerless in the face of the finiteness of life, but scientific research can provide opportunities for significant partial solutions.

- it has become clear that religious identity demands more and more space for itself, as the religious is more viable against the unfaithful, liberal and materialistic ideologies are by their very nature selfish, individualistic, and logically doomed to self-destruction.

These seismic changes of our time require a new way of thinking from everyone. The starting point for this new way of thinking is the new fact that humans have not simply "shrunk the

25 There have been more than 5,000 satellites in space, but only 2,000 are still active. Scientific models estimate there are more than 128 million pieces of space debris that are larger than $1 \mathrm{~mm}$, and 34,000 pieces larger than $10 \mathrm{~cm}$.

26 www.ats.aq/e/antarctictreaty.html 20-01-2021

27I.M.:552. 
Earth to themselves. ${ }^{28 ،}$ but are indeed an unquestionable community of fate in present-day interconnection.

While Marx, in the Communist manifesto, talks about "The bourgeoisie has transformed the production and consumption of all countries into cosmopolitans by exploiting the world market. ${ }^{296 ،}$.

In this interconnectedness, it is essential to develop new normative orders that were not in previous periods and which are capable of effectively controlling the life of the entire human community. It has become clear that democratic, nation-state-related legal order alone is not suitable for global regulation. Partly because national legislation is essentially national, partly because global regulators are often not legal, but rather based on customs, understandings or even regulations, codes, or even standards and protocols.

However, in addition to analyzing the details, a more important question is whether a guiding principle can be found that can be subordinated in a sustainable way, and all other regulations, such as norms, can be found. Of course, this is a utopia as a general principle, since neither 'world religion, world ethic, world law' can be achieved - at least based on our current experience. However, it may be feasible to link religions, morals and rights along a common guiding principle, solidarity.

It seems logical to rethink and extend the principle of solidarity, which was developed at the roots of the concept of natural law and which was later highlighted in Christianity, into a global one. According to this, all men are equal because of their unrepeatable and eternal dignity. The basis of this dignity is the freedom of the person and the resulting sense of duty, as Immanuel Kant has made clear in the pages of pure reason. This is the result of the altruistic principle envisioned in the golden rule, the central idea of which is that one cannot imagine our own healthy self-interpretation without the well-being of the other person. In other language, we are dependent on each other, and we must raise awareness of this interdependence to the level of our actions. Partly at the level of individual assistance and partly at the level of functioning regulatory structures over states.

The principle of global regulation is collective morality, consensus, or at least dialogue on core values. The list of formally defined human rights is not sufficient, but we need an individual and collective internal belief that can adapt to the world of good and evil, just and unjust. In our world, especially in Western societies, it would be a great achievement if we could at least have a substantive discourse on these issues and not think that we are already 'too good and bad'.

Global morality must be underpin by national and supranational law, which is able to comprehend a conscious relationship with the community-forming processes of both morality and religions. In practice, this also means building procedures for morality, religion, and communication with technical regulatory modes, in addition to pure legality. The basic category 'Welt ethos' should be developed ${ }^{30}$ the global principles of ius publicum ecclesiasticism should

\footnotetext{
28Nietzsche, F., Im-yen, Zarathustra, 1908, 8.

"What is love? What the hell? What's the longing? What is the star?" the last man asks and squints. The earth then became small, and the last man leaped upon him, who made all things small. Its species is indestructible and the species of fleas on Earth, the last man alive for the longest time.

29 www.marxists.org/magyar/archive/marx/1848/communist-manifesto/ch01.htm\#s1, 2020.11.01.

30Listl, J., Aufgabe und Bedeutung der canonistischen Teildisiplin des Ius Publicum ecclesiasticum. Die Lehre der katholischen Kirche zum Verhältnis von Kirche und Staat seit dem zweiten Vatikanischen Konzil, in: Kirche im freiheitlichen Staat.Schriften zum Staatskirchenrecht und Kirchenrecht. Erster und zweiter Halbband, 1996.
} 
be developed and global issues of technical regulation for standardization bodies should also be settled.

Meetings of professional organizations representing all people who are truly concerned with sustainability should replace the meeting of rich leaders of rich countries. This includes religious organizations, which are also embodiments of the wisdom of millennia.

A first sign of all this, even more of an illusion, is Pope Francis' encyclopedia "Fratelli tutti". 31 ، The interesting thing about the letter is that it constantly links to the Ahmad Al-Tayyab prayer, and after its publication, other Christian leaders, such as the Ecumenical Patriarch Bartholomay's of Constantinople, joined him. Thus, it could be said with poetic hyperbole that for most of the world we can talk about writing with guiding, normative content. The central idea of the letter is to call on individuals and political communities alike to act together in the name of universal brotherhood. There is a reason paragraph 281 says that peace between religions is possible. In order to help the common good and the poor, representatives of religions are willing to negotiate with each other.

The encyclopedia reveals that the world has shrunk so small that it is necessary to experience each other's presence directly. This means that nearly 10 billion people have to live as brothers in close proximity to each other. This is a very serious organizational task. I mean, in a bad case, instead of brotherhood we can wipe each other out. In the organizational task, the representatives of the now devilized political profession are also of great importance. They are responsible for the legal and ethical levels ${ }^{32}$ of organization ${ }^{33}$.It is very interesting, and perhaps only from English terminology, that the latest instruments of normative regulation (code of conduct, standard) are listed in the last summary pages of the Encyclique: "In the name of God and of everything stated thus far, [we] declare the adoption of a culture of dialogue as the path; mutual cooperation as the code of conduct; Reciprocal understanding as the method and standard ${ }^{34}$.

A culture of dialogue, a genuinely well-established social discourse ${ }^{35}$, should develop codes of ethics governing cooperation, in which mutual understanding is the basis for methodology and standardization. However, this fine principle will only be an exercise if there is enough strength and resources to develop the related procedures and to establish the right organizations. This could open up a new way of cooperation between the state and the Church.

The task is to reverse the process by which both morality and politics become pure calculation, "physics". The world of social systems and subsystems takes into account the principle of usefulness rather than the concepts of good and evil ${ }^{36}$.In this sense, the law is transformed into a purely technical concept, one that supports the stronger. ${ }^{37}$

\footnotetext{
31www.vatican.va/content/francesco/en/encyclicals/documents/papa-francesco_20201003_enciclica-fratelli-tutti.html, 2020.11.01.

32Fratelli tutti 126, We are really speaking about a new network of international relations, since there is no way to resolve the serious problems of our world if we continue to think only in terms of mutual assistance between individuals or small groups. Nor should we forget that 'inequity affects not only individuals but entire countries; it compels us to consider an ethics of international relations". Indeed, justice requires recognizing and respecting not only the rights of individuals, but also social rights and the rights of peoples.
}

33In the Encyclical, the word Politic appears 102 times, while the word "Jesus" appears only 33 times.

34Fratelli tutti, 285.

35Habermas, J., Change of Social Publicity, Budapest 1999

36Birher N., Law, Morality, Religion, in Birher N., Homicskó Á., Ethical foundations of the operation of ecclesiastical institutions, Budapest $2019,9-24$.

37What is now happening and drawing us into a perverse and barren way of thinking, is the reduction of ethics and politics to physics. Good and evil no longer exist in themselves; there is only a calculus of benefits and burdens. As a result of the displacement of moral reasoning, the 
Beyond the order of law, political responsibility is the "political charity", a selfless activity aimed at the common good. Since classical Greekism, it has been clear that the two basic types of leader are selfish and altruistic. We also know that selfishness always leads to a "febrile state", while altruism leads to peace. It is also well known that Hegel set the creation of collective altruism in the state as one of the fundamental goals of the philosophy of law.

However, the failure of these beautiful ideates is clearly visible in practice. The question is, at the current level of organization, can society develop a more effective regulatory system? In any case, there is no longer a lack of well-understood self-interest or pressure from unsustainability to create a fairer society in the world by redefining concepts of law, morality, religion, describing their relationship systems, and using new objective techniques and standards of regulation.

As an encouragement, here is Lincoln's famous quote, in which, after the Civil War, he connected the unity of the nation with the love of help, the charity, and the absolute concept of truth:

With Malice toward none, with charity for all, with firmness in the right as God gives us to see the right, let us strive on to finish the work we are in, to bind up the nation's wounds, to care for him who will have borne the battle and for his widow and his orphan, to do all which may achieve and cherish a just and lasting peace among ourselves and with all nations ${ }^{38}$.

After what has been discussed so far, let us move on to the other global way of regulation, the fully formalized regulation, whose task is to 'make things work'. This is not about basic human values in the first step, but about increasing efficiency. Another issue is that efficiency can only make sense if we know why we should be effective. Lest the slogan of the motorized generations be true of us: "we do not know where we are going, but at least we will get there quickly".

\section{Standards}

Standards are new means of regulation that may be suitable for objective process control. Here, it is no longer simply states, facts, but complex processes (which convert inputs into outputs during a particular activity). When regulating, we must be able to keep the regulated property at a specified value.

Another issue, despite the fact that the meaning of the word's standards, specifications, protocols and standards is unclear and is often used interchangeably, is yet these are the regulators that define much of today's regulatory processes.

For the time being, basically accepting the conceptual "benevolent gloom of uncertainty", we are trying to define some kind of standard. It can be a standard that we accept as a basis for comparison, either because of public victory or because of the authority of an authority. In this context, the standard may be an object considered to be of normal size or variety. In addition, a rule or principle on which the judgment is based, or an expectation laid down in advance is standard.

law is no longer seen as reflecting a fundamental notion of justice but as mirroring notions currently in vogue. Breakdown ensues everything is "leveled down" by a superficial bartered consensus. In the end, the law of the strongest prevails., Fratelli tutti, 210.

38Abraham Lincoln: Second Inaugural Address" Saturday, March 4, 1865.Inaugural Addresses of the Presidents of the United States 
As long as the law seeks to regulate the consequences of events that have typically occurred, process regulation seeks to adapt the result of the process to the "standards" 39 . Although several detailed analyses have already been carried out on the processability of the law, Csaba Varga's work entitled "Law as a Process" deserves special mention ${ }^{40}$, but we still regard the law not as a process regulator, but as an instability to date as an ex post evaluation.

This approach is broken by the way, in which the regulatory approach to the process approach, such as a code of ethics or some kind of standard, is broken.

A process is a series of typically cyclically repetitive tasks that produce outputs from inputs. The process uses resources to implement tasks.

Iso 9001 (9001:2000 in our study) provides a summary definition of the process approach, as follows: 'This international standard promotes the use of a process approach in the design, implementation and improvement of the efficiency and efficiency of the quality management system'. "For an organization to function effectively and efficiently, it must identify and manage a number of interrelated processes. Any activity that uses resources and is routed to convert inputs to outputs can be considered a process. The output of one process is often also a direct input to the next process."

The application of a system of processes within an organization, together with the definition, loan effects and management of these processes, can be considered as a 'process approach'.

One of the advantages of a process approach is that it ensures continuous control of the relationship between processes within the system and the combination and interaction of processes along the following lines:

a) Understanding and meeting requirements,

b) The need to rethink processes in terms of added value,

c) Learn about how the process works and how it works, and

d) Continuous improvement of processes based on objective measurements.

Although we can see an accelerating feedback loop in legislation (newer and newer legislation and frequent legislative amendments), in the world of standards and process regulation, this is built into the system and deliberately designed, for example, by un. Deming cycle (PDCA)

"Plan-Do-Check-Act" (PDCA) means the following according to ISO 9001:

Plan (planning): Set the goals and processes needed to achieve results that are in accordance with customer requirements and organization policy.

Do (implementation): The introduction of processes.

Check (checking): Monitoring and comparing processes and products with policy, objectives and product requirements, as well as presentation of results.

Act (measure): Take measures to continuously improve the functioning of the process ${ }^{41}$.

Gabor Veress, creative editor, is one of the first to detail the relationship between standards and legislation in his 1999 work "Quality Management of Higher Education Institutions". It is clear here that, in addition to legislation, there is a need for process control by non-legal means in order to achieve an adequate quality of education.

\footnotetext{
39Birher N., Development of other norms in the context of modern technology regulation, parallel to legislation, www.ajk.kre.hu/images/doc4/dokumentumok/Egysegesitve_tehnologiai_kihivasok.pdf, downloaded:2020.12.04. 40Varga Cs., The Law as a Process, Budapest 2002.

41Quality management systems. Requirements (ISO 9001:2000)
} 
The first illustration shows how the Deming cycle and the standardization can be linked in process control.

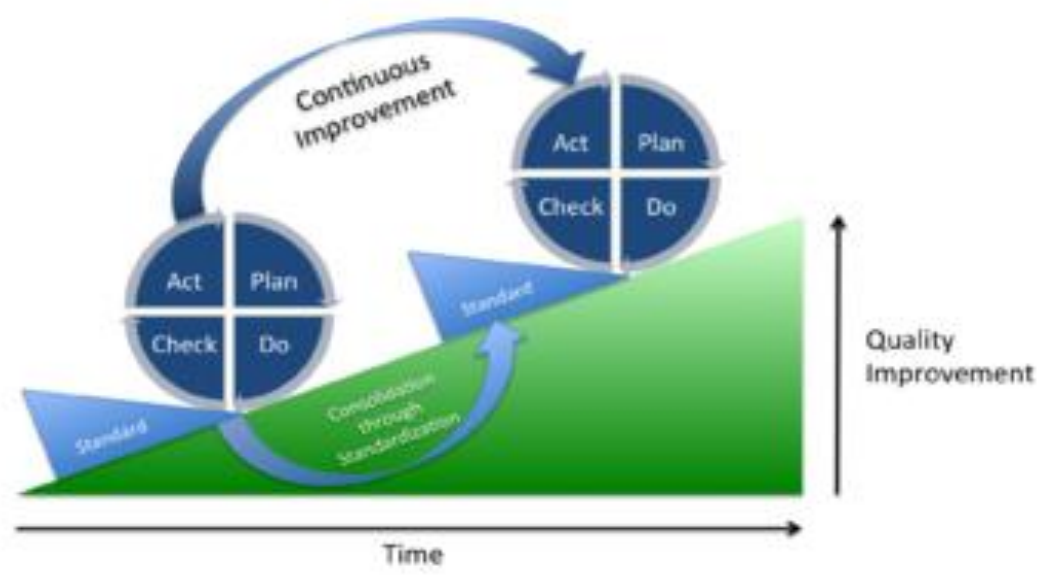

Diagram: standardization and PDCA cycle (Source: Wikipedia PDCA)

Among the improved models, the so-called PDCA-SDCA model, in which the "S" refers to standardization, should be highlighted. If we have planned, executed, checked something back and found it to be good, it must be generalized, specifying the rules for its application (standardization). Implementation should then be measured against standardized requirements.

New emphasis on national and democratic legislation

Future politicians must therefore take these new aspects into account by changing their legislative responsibilities significantly as a result of the following:

1, The horizons are expanding globally, and regulation at international level will play an increasing role in regulation

2, Regulation should be explicitly ethical, as global ethical problems become more common.

3, And legislation must also be directly linked to the 'Internet of Things', i.e. it is necessary to regulate not only persons and persons' contacts, but also machines and machine connections.

The third aspect is still largely in the area of "de lege ferenda", but the first two already directly affect our daily lives.

However, in the case of industry 4.0, we are already seeing that the regulation of our daily lives describes and manages human and machine cooperation in a more spurred way than a positive right. ${ }^{42}$. As a result, regulation in machine-to-machine and human-machine communication can be implemented as purely formalized regulation. On the one hand, a system of decision-making is established with complete certainty, and on the other, the "summum ius summa iniuria" (the completeness of the law is the completeness of the law) is threatened precisely because of this. We have come to an area of regulation where, in the interests of man, along the principle of justice, we must once again return to the application of natural law in accordance with norms, or at least to a unified, human-centred ethics.

This applies in particular to solving the globalized transnational regulatory tasks that define the mindset of Industry 4.0. Uniform regulation is needed on practical issues such as what decisions 
autonomous vehicles take, how drones can intervene in armed conflicts, and what content can be posted in community forums. However, just as important will be the automation of stock market trade or the machine shaping of monetary policy. A more common practical example is the cases in which an algorithm may terminate the employment relationship, taking into account the employee's measured activity, or how another programme may decide to take conditional leave ${ }^{43}$.

It is becoming increasingly clear that the horizons of interpretation of the law linked to classical nations and representative democracy are expanding in the age of Industry 4.0. WoT (Internet of Things) clearly requires transnational regulation, specifically through industry experts. At present, the legislators of each country are not necessarily prepared to place the rulemaking as a whole under democratic control in this new context. In the wrong case, these controls become even weaker in the age of machine connectivity, simply because of a lack of expertise and the transnational nature of the area to be regulated.

Because of these facts, it is important that jurisprudence broadens its horizons beyond the classical approach and, in addition to a kind of 'regulatory science', ensure that the interests of the human community are constantly respected in the age of mass and sometimes automated design of standards and protocols. The complementarity of complexity science can be regulatory science, which is capable of placing new tools for regulating human life in the norms of legal-morality-technical regulations (possibly religion) ${ }^{44}$. It is important to draw attention to the fact that more and more important international technical regulations (standards, standards, etc.) have a direct impact on citizens' lives, when these regulators do not actually have any democratic control what so subject.

This is precisely why it is vital for responsible nations to be active not only in legal norms, but also in shaping other normative orders previously discussed. Of course, in addition to building the necessary personal relationships, the existence of qualified professionals is an essential condition for this. This is why it is important that legal training also a monitor these new processes.

\section{European efforts to 'regulate'}

Protocols and standardized communication channels enable the creation of global systems from which individual national regulations are virtually incapable of deviating, thereby creating an unprecedented concentration of power. This process is described in the G7 ICT and industry minister`s declaration making the next production revolution inclusive, open, and secure Turin, 25 - 26 September 2017, with points 40 and 41 clearly taking a position in favor of a global, standard-connected world.

"We believe that the application of industry-generated voluntary international technical standards in an open, transparent and consensual manner is critical to moving towards a digitally connected world. These are instruments for promoting economic growth, innovation, and productivity, which underpin competitiveness and interoperability. In order to maintain and extend global connectivity, economic interaction, and international standards should be

\footnotetext{
43Supreme court of Wisconsin, 2015ap157-cr, state of Wisconsin V. Eric 1. Loomis.

44Mashhad Al-Allaf, modern technology, preventive ethics, and the human condition: should we renew our moral philosophy for the ever-

renewed technology?

www.academia.edu/9342974/modern_technology_preventive_ethics_and_the_human_condition_should_we_renew_our_moral_philosophy_ for_the_ever-renewed_technology, 16 September 2019.
} 
prioritized over national or regional standards. When implementing international standards, regional or national standards shall not contradict the original international standard."

However, we do not get an answer as to who can create these rules and with what legitimacy.

The problem was raised as early as the 1930s, with only a principled edge at the time. That's how Hans Kelsen put it: "After all, the trend of the whole legal change marked here is to cross the line between international law and the legal order of individual States, so that the ultimate goal of the development of the law for real increasing centralization is the organization of a universal world community, i.e. the development of a world state.... Only the cognition unit of all rights is given; in other words, it is possible to see international law, together with the legal order of each State, as a uniform system of standards - in the same way as we normally regard the legal order of each State as a unit. ${ }^{45}$

There is a clear willingness to develop a unified, supranational regulatory language based on pure legal science. Today, we see that this kind of pure legal science does not provide sufficient grounds for international cooperation. Although technically effective at establishing machine communication, it is unsuitable for regulating the communal life of a moral and religious person. A new common communication platform should therefore be established in which natural law can play an important role, due to its interconnected nature.

The issue of uniform normative language naturally concerns supranational organizations, such as the European Union. This is precisely why the EU Commission has set up an international expert group to develop reliable AI principles. It is interesting that it is already noted in the introduction that compliance with the requirements of law, morality and 'robustness' is essential for regulation.

"The aim of the guidelines is to support reliable AI. Reliable AI has three components that must be fulfilled throughout the life cycle of the system: (1) it must be legal; it must be ethical in accordance with applicable laws and regulations (2), ensuring compliance with ethical principles and values, and (3) robust, both technically and socially, since even with good intentions, AI systems can cause accidental damage. Each component is necessary on its own, but not sufficient to achieve reliable AI. Ideally, all three components work together harmoniously, and their activities overlap. If, in practice, tensions arise between these components, society should strive to coordinate them ${ }^{46}$.

The terminology of the document and its relationship to the normative orders are the same as before. Human rights terminology, but it is highly incomplete, does not, for example, address the fundamental essence of the human-machine relationship or define man as a transcendental being.

It should be noted here that the human rights narrative was intended in liberal democracies to perform the task of coordinating norms. However, he could never achieve this in its entirety, for he could only seize one's freedom in the sense of freedom from something, not freedom of something. In other words, the principle of "everything is free, which is not forbidden" ignored the question of "what should I do to be human". As we have shown before, two sides of the principle can be brought together by natural law in a single structure.

Previous research has shown that legislation is insufficient for innovative technologies. This is partly due to the dangers inherent in technologies and partly to the slowness of regulation. "De

45Kelsen, clean law school...

46Ethics Guidelines for Trustworthy AI www.ec.europa.eu/futurium/en/ai-alliance-consultation/guidelines/1\#Human\%20agency, 18 May 
lege lata" regulation is always behind the development of technologies, and "de lege ferenda" regulation can be more of a science fiction experiment in the age of modern technologies. It is therefore necessary to take a new preventive approach, linking the levels of normativity that can be understood in international communication.

It complicates the situation further and partly contrasts with the growing need for transcendence in humans. Because of the evolutionary advantage of religion, (regulative, integrative, interpretative function ${ }^{47}$ ) communities that also use religious norms to survive seem to be much more viable. These people will be human factors in H-CPS systems. It is an open question to link these two completely different levels of regulation, religion, and standards. This, of course, means not only will the worker have time to pray in advance, for example, but also whether the worker will even be willing to participate in the rigid world of rules. Europe's recent history is also about this issue.

Artificial Intelligence will change society. It will open opportunities, but also risks as well. Artificial Intelligence and learning systems can improve the lives of many people if they are properly used. ${ }^{48}$ For this to succeed, politics, business, science, and society must jointly discuss open questions and explore the opportunities and risks of technological progresses. Comprehensive research is more important than ever to be able to understand technical developments from an ethical, social, and legal perspective. "A year spent in artificial intelligence is enough to make one believe in God." 49

Europe is the largest market player in the world. Europe must therefore set itself the goal of achieving a share of value added for AI that corresponds to its economic strength. This requires cooperation in Europe, more research in close cooperation between business and science, but above all a new entrepreneurial dynamic in the field of AI. Artificial intelligence has reached a new stage of maturity. In many sub-areas of AI, new hardware with new algorithms has led to more performance and data from networks and the Internet of Things to new areas of application. The foreseeable improvements in hardware and software mean that the existing potential of science and industry is far higher. This offers an enormous opportunity for the economy, but at the same time, it is also an enormous challenge for the science and the innovative capacity of companies.

Artificial intelligence is a sub-area of computer science and is considered the next important development stage of digitization. The aim is to design technical systems in such a way that they can deal with problems independently and adapt themselves to changing conditions. So, these systems can learn and deal with uncertainties (probabilities) instead of being programmed

47Idler E., McLaughlin, J., Kasl S., Religion and the Quality of Life in the Last Year of Life, doi:10.1093/geronb/gbp028,

https://www.ncbi.nlm.nih.gov/pmc/articles/PMC2697501/, 18 May 2019

48 A study by the World Intellectual Property Organisation WIPO (WIPO Technology Trends 2019 Artificial Intelligence, provides a good overview of AI patent applications worldwide.

www.wipo.int/edocs/pubdocs/en/wipo_pub_1055.pdf)

WIPO Technology Trends 2019 Artificial Intelligence

(C) WIPO, 2019 First published 2019 World Intellectual Property Organisation 34, chemin des Colombettes, PO Box 18 CH-1211 Geneva 20, Switzerland ISBN: 978-92-805-3007-0

49 www.en.wikipedia.org/wiki/Alan_Perlis Alan Jay Perlis (April 1, 1922 - February 7, 1990) was an American computer scientist and professor at Purdue University, Carnegie Mellon University and Yale University. He is best known for his pioneering work in programming languages and was the first recipient of the Turing Award. 
classically. ${ }^{50}$ Sub-areas of AI are the following: Deduction systems, mechanical proof; Knowledge-based systems; Pattern analysis and pattern recognition, machine learning; Robotics and autonomous systems and Multimodal human-machine interaction.

Regulating artificial intelligence is a major concern of the EU stressed Commission President Ursula von der Leyen ${ }^{51}$. The project is considered so important that the European Parliament has set up a special committee. Before the pandemic and its economic consequences upset the EU's priorities, digitalization was the central theme alongside the fight against climate change. The legal framework for AI played a prominent role in this. On the one hand, because of the economic importance, learning algorithms and the machines they control are likely to revolutionize large areas of the economy and create additional prosperity. However, AI is also central to the EU's self-image, since Europe could be the first major economic area in the world to adopt binding rules for the development and use of new technology for the future. The Commission will present a draft law in 2021, and the European Parliament has its own ideas.

For example, a project group of such experts published a work entitled "The Malicious Use of Artificial Intelligence". ${ }^{52}$ The group includes the universities of Stanford, Yale, Oxford, and Tohoku, as well as developers of Microsoft, Google and its subsidiary, the currently leading AI company DeepMind. One of the concrete examples that the researchers mention in their call is the development of image recognition and generation by AI. She was still on the stand in 2014 that she could only create grey-veiled phantom images. Meanwhile, with so-called deep-fake technologies, it is possible to transfer faces with credible facial expressions into videos to foreign bodies. In view of the recent history of political manipulation, this, in turn, is a form of destructive AI application, which is difficult to stop.

The possibilities of such abuse range from unimagined dimensions of hacking (not only from computers, but also from AI-driven systems such as drones, vehicles, robots or autonomous weapons) now and in the near future, to an arms race on all issues of cyber security, which they divide into digital, physical and political security. The experts also propose solutions. Centralizing artificial intelligence would be one way to prevent abuse. However, they also recall the NATO Conference 1968 in Bavaria, Garmish, which laid down the foundations for software development that are still norm today, and the moratorium that biological research proclaimed in 1975 in Asilomar, California (currently used in gene research as a basis for new selfrestrictions). The reminders are even optimistic: the development of AI was at a point where one could still intervene together. "When people and machines work together, artificial intelligence will reveal our true potential." ${ }^{53}$ AI algorithms would help humanity to improve the real world, be it in the development of new medicines or materials, or in robot research.

50 The Next Decade in AI: Four Steps Towards Robust Artificial Intelligence

2002.06177.pdf (arxiv.org) www.arwiv.org/ftp/arxiv/papers/2002/2002.06177.pdf 15.01.2021

51 European AI Alliance www.ec.europa.eu/futurium/en/node/3432/terms/all/Artificial\%20Intelligence 15.01.2021

52 The Malicious Use of Artificial Intelligence: Forecasting, prevention, and mitigation 1c6q2kc4v_50335.pdf (wsimg.com) 15.01.2021

53 Pega White Paper Take control of your AI www.pega.com/artificial-intelligence-business 15.01.2021 


\section{Outlook: Regulatory complexity in education}

Recognizing the functioning of regulatory complexity requires new teaching methods. In all areas of training, it is necessary to outline the rules governing individual action. It should be pointed out that the norms have different forms of appearance, i.e. not only can the legal norm be considered the norm, but also that these standards are linked in a complicated way.

In legal education, it should be pointed out that the seemingly clear principles of pure law do not work in many areas of social life. It is also important to stress that, in addition to legislation, new ways of regulating, particularly in international terms, are emerging. As a first step, it may also be of particular importance in legal education to present the ways in which standards are to be regulatory, even though quality assurance standards.

In addition to the transformation of the content of training courses, it is a general phenomenon in education that the quality of education is ensured through the operation of quality management systems. It has been a recurring narrative for decades to improve the quality of training. There were a number of efforts to achieve this quality through the mandatory introduction of different quality management systems, constantly ignoring the fact that 'quality cannot be obliged because quality comes from within'.

Quality is the culture of the organization, its need to improve its processes. Since what is "better" for a process cannot be required by law, the amount of "paper production" has been increased or the market for consultants has been expanded by mandatory schemes.

The positive change in the past years with regard to "compulsory" systems for higher education is that the Hungarian Accreditation Committee (MAB) is increasingly operating as a contracted service provider, not as a public authority or office.

It must also be treated as a positive phenomenon that the quality management systems required for educational establishments have started to wear out in recent years, as they have not produced sufficient results, despite their often-excellent development. I am also thinking of CEDEFOP's well-developed quality management system, the practical application of which in the field of vocational training has almost ceased in a few years. The situation is also well characterized by the fact that the 2009 EQAVET document is still referenced on the official CEDEFOP website, or under the headlines tab, the latest news will be sent to the reader from March 2018.

The problem, therefore, is not with the systems itself, but with their reasoning for the organisms. The compulsion will be administrative at most, but certainly not quality.

We need to bring complicated process descriptions back to a simple master-student relationship. However, this relationship must be regulated, measurable and accountable, so as not to create an impediment to administrative burdens to ensure that quality can be justified.

This can best be achieved through the following activities:

- Raising awareness of quality as a social and individual responsibility in the trainer,

- Quality as motivation in the student,

- Create the simplest documentation system possible,

- Objective definition of measurable criteria for quality, e.g. completion of further training courses, professional competitions, master's prizes. 


\section{Summary}

We can say that the recognition of regulatory complexity must go through education as a whole, partly as a methodology, i.e. as an art of coordinating different regulators. Consider, for example, how many types of regulators work together in a Church educational institution to achieve the highest possible educational quality. In addition to regulating the legislation, there is a need to integrate religious and moral standards and ensure the quality of processes, as well as the creation of various codes of conduct. This complex network of regulation creates a working regulatory complexity.

On the other hand, it is also necessary to present this diverse link of regulation with the need for scientificity, highlighting that it is not at all sufficient to think only and exclusively in the role of the regulator of law in today's society.

It is important that there is an increasing number of forward-looking initiatives in this area. Rabbi Sacks ${ }^{54}$ describes the story of a man getting lost in the woods, unable to find a way out after days. All of a sudden, he hears footsteps, someone is coming however, and the other man turns out to be lost, too. At least there is two of them now, and it will make it a lot easier for them to find a way out.

It is not easy to find a way out in the densities of norms. Trust is now weakened in all norms, but at the same time, our self-awareness has increased. If law, morality, religion causes problems, then they must be solved by law, morality, religion. This is possible if we are not looking for conflicts, but for cooperation, if we are not to interfere in each other's internal affairs, but to look for ways of cooperation. Just because we know and accept other rights, morals, and religions does not mean that our own norms need to be weakened. Moreover, on the contrary, acceptance of otherness strengthens us. After all, we are all driven by the same desires and promises ${ }^{55}$.

54Sacks, J., The Dignity of Difference: How to Avoid a Clash of Civilisations,

www.digitalcommons.sacredheart.edu/cgi/viewcontent.cgi?article=1134\&context=shureview, download:2020.12.06.

55Hanan, A., Pedagogy of difference: Rabbi Jonathan Sacks and education, www.jpost.com/opinion/pedagogy-of-difference-rabbi-jonathansacks-and-education-651252, download:2020.12.06. 